\title{
LERCAFÉ: NOVO TESTE PARA ESTIMAR O POTENCIAL GERMINATIVO DE SEMENTES DE CAFEEIRO (Coffea arabica L.) ${ }^{1}$
}

\author{
LUCILÉA SILVA DOS REIS²; EDUARDO FONTES ARAÚJO3; DENISE CUNHA FERNANDES DOS \\ SANTOS DIAS ${ }^{3}$; CARLOS SIGUEYUKI SEDIYAMA ${ }^{3}$; ROBSON CELESTINO MEIRELES ${ }^{4}$
}

\begin{abstract}
RESUMO - Com o objetivo de utilizar o hipoclorito de sódio no desenvolvimento de novo teste para avaliar rapidamente a qualidade das sementes de cafeeiro, por meio da estimativa da germinação, o presente trabalho foi realizado com quatro lotes de sementes de cafeeiro (Coffea arabica L.), cultivar IAC Catuaí 44 e quatro lotes da cultivar Rubi. A porcentagem de germinação das sementes foi estimada pelo teste desenvolvido, denominado LERCAFÉ, em duas metodologias. No método 1, as sementes tiveram seu pergaminho removido manualmente e foram imersas em solução de hipoclorito de sódio a 2,5\%, por 3 horas. Posteriormente, as sementes foram lavadas e avaliadas visualmente. No método 2 , as sementes com pergaminho foram imersas em hipoclorito de sódio a 5,0\% por seis horas, lavadas e imersas em água destilada por 40 min e avaliadas. Na avaliação visual das sementes, foram consideradas não germináveis as sementes que apresentavam formação de coloração esverdeada na região embrionária e que não apresentavam embrião visível; a qualidade dos lotes também foi caracterizada pelo teste de germinação. Os dois métodos do teste apresentam alta correlação com o teste de germinação. Conclui-se que o uso do teste LERCAFÉ na avaliação rápida das sementes de café é de baixo custo, de fácil execução e interpretação, permitindo estimar com precisão e rapidez o potencial de germinação das sementes de cafeeiro, além de apresentar características não destrutivas, favorecendo a avaliação das plântulas provenientes das sementes testadas.
\end{abstract}

Termos para indexação: viabilidade, exsudato, Coffea arabica.

\section{LERCAFE: NEW TEST TO ESTIMATE THE GERMINATION OF THE COFFEE TREE SEEDS (Coffea arabica L.)}

\begin{abstract}
With the objective of using the hypochlorite of sodium in the development of a new test to evaluate quickly the quality of the coffee tree seeds, through the estimate of the germination, the present work was accomplished being used four portions of coffee tree seeds (Coffea arabica L.) cv. IAC Catuaí 44 and four portions of cv. Rubi. The percentage of germination of the seeds was estimated by the developed test, denominated LERCAFE, in two methodologies. In the method 1 , the seeds had its parchment removed manually and soon after they were immersed in solution of hypochlorite of sodium to $2,5 \%$, where they stayed for 3 hours. After that, the seeds were washed and later evaluated visually. In the method 2 , the seeds with parchment were immersed in hypochlorite of sodium to $5,0 \%$ for a period of 6 hours and the seeds that were submitted to this method were washed and immersed in distilled water by 40 minutes and later appraised. Like this, in the visual evaluation of the seeds, were considered non-germinated the seeds that presented formation of greenish coloration in the embryonic area and the seeds that didn't present visible embryo; the quality of the portions was also characterized by the germination test. The two methods of the LERCAFE test presented increase correlations with the germination test. The use of the LERCAFE test in the fast evaluation of the seeds of coffee, has a low cost and an easy execution and interpretation, allowing estimate accurately and with quickness the potential of germination of the coffee tree seeds, besides presenting non destructive characteristics, favoring the evaluation of seedlings deriving from the tested seeds.
\end{abstract}

Index terms: viability, exsudate, Coffea arabica.

${ }^{1}$ Submetido em 05/05/2009. Aceito para publicação em 24/09/09. Parte de tese de Mestrado em Fitotecnia na Universidade Federal de Viçosa.

${ }^{2}$ Doutora em Genética e Melhoramento de Plantas - UENF - Campos dos
Goytacazes, RJ. lucileasreis@yahoo.com.br

${ }^{3}$ Professor Departamento de Fitotecnia - UFV, efaraujo@ufv.br

${ }^{4}$ Doutor em Produção Vegetal - UENF, robsoncm@ifes.edu.br 


\section{INTRODUÇÃO}

Trabalhando com sementes de café, Kikuti (2000) ressaltou que a qualidade de um lote de sementes é fator essencial no planejamento e implantação de qualquer programa de produção agrícola, uma vez que o emprego de sementes de boa qualidade propicia boa emergência, obtendo-se plantas vigorosas e uniformes, com consequências positivas e diretas na produtividade.

Sementes de cafeeiro, notadamente, apresentam viabilidade curta e germinação lenta, sendo assim, alvos permanentes de pesquisas, principalmente no que tange a avaliação rápida de sua qualidade. Deste modo, a combinação destes fatores constitui o principal problema na divulgação de informações precisas sobre o potencial fisiológico das sementes, uma vez que o método oficial para esta avaliação é o teste de germinação que, embora conduzido em condições ótimas, exige período mínimo de 30 dias para a obtenção dos resultados o que, conforme Dias e Silva (1986), pode não mais condizer com o atual estado fisiológico das sementes.

A capacidade germinativa e o real potencial fisiológico das sementes de café são informações primordiais em decisões que envolvam comercialização, utilização ou descarte de um lote. O uso de testes que propiciem a avaliação da qualidade das sementes de forma mais rápida e eficaz vem colaborar com o suprimento de demandas geradas pelos produtores de sementes, viveiristas e laboratórios de análise, no que diz respeito ao destino dos lotes de sementes após a colheita.

Para que os testes utilizados na avaliação da qualidade de lotes de sementes desempenhem sua função de forma adequada, de modo a possibilitar seu emprego em escalas mais amplas, é fundamental que sejam de execução fácil e rápida, além de apresentarem baixo custo e alta correlação com os testes utilizados como análise de rotina em laboratório (Fernandes et al., 1987).

Em função disto, diversos testes vêm sendo desenvolvidos com o objetivo de determinar a qualidade de sementes, seja pela estimativa do vigor, capacidade germinativa ou pelo percentual de danos mecânicos com o máximo de precisão e rapidez. Dentre eles, estão listados testes classificados como rápidos como os testes de tetrazólio, de condutividade elétrica, de $\mathrm{pH}$ do exsudato (fenolftaleína), o verde rápido, da tintura de iodo, entre outros.

Contudo, os meios mais confiáveis de avaliação da viabilidade de sementes ainda são o teste de germinação, que demanda muito tempo para sua realização, e o teste de tetrazólio, que apesar de estimar o potencial germinativo de sementes, é muito trabalhoso e exige maior investimento em mão-de-obra qualificada.

Deste modo, o presente trabalho teve como objetivo utilizar o hipoclorito de sódio no desenvolvimento de novo teste para avaliar rapidamente a qualidade das sementes de cafeeiro.

\section{MATERIAL E MÉTODOS}

Os trabalhos foram conduzidos no Laboratório de Análise de Sementes do Departamento de Fitotecnia da Universidade Federal de Viçosa (UFV), em Viçosa, MG, utilizando-se sementes de cafeeiro (Coffea arabica L.) cultivar IAC Catuaí 44 e Rubi, provenientes da área experimental da Fazenda Fertilizantes Heringer, no município de Manhuaçu, MG.

Os frutos colhidos para a extração das sementes apresentavam-se no estádio de maturação denominado cereja, sendo que após essa etapa os mesmos foram submetidos aos processos de despolpamento e fermentação em água por 24 horas para retirada da mucilagem. Em seguida, as sementes foram lavadas em água corrente e dispostas sobre telado à sombra para remoção do excesso de umidade. Após isso, efetuou-se a eliminação de sementes que se apresentavam chochas, danificadas e brocadas, conforme os procedimentos para obtenção de lotes comerciais.

Para a obtenção de lotes com diferentes potenciais fisiológicos, as sementes das duas cultivares foram divididas em oito porções, totalizando quatro lotes de cada cultivar. A diferença de qualidade dos lotes foi obtida com o armazenamento, uma vez que as avaliações foram realizadas com as sementes recém-colhidas e aos 30,60 e 90 dias. Os lotes foram dispostos em bandejas plásticas onde permaneceram armazenados em condição de ambiente com temperatura média variando entre $20-25^{\circ} \mathrm{C}$. As sementes tiveram seu teor de água determinado para conhecimento das condições específicas de cada lote.

Teor de água das sementes-O teor deágua das sementes de cada lote foi determinado por meio do método da estufa a $105 \pm 3{ }^{\circ} \mathrm{C}$, por período de 24 horas, utilizando-se duas repetições de aproximadamente 30 gramas de sementes sem o pergaminho, conforme Brasil (1992), sendo os resultados expressos em porcentagem (base úmida) (Tabela 1).

Além disso, os lotes foram submetidos ao teste de germinação para a caracterização do potencial fisiológico das sementes e verificação de sua capacidade germinativa, estabelecendo, assim, padrão de comparação para os outros métodos de avaliação. 
TABELA 1. Teor de água (base úmida) de diferentes lotes de sementes de Coffea arabica $\mathrm{L}$., cultivares IAC Catuaí 44 e Rubi.

\begin{tabular}{ccc}
\hline Cultivar & Lote & Teor de água (\%) \\
\hline IAC Catuaí 44 & 1 & 28,1 \\
IAC Catuaí 44 & 2 & 25,0 \\
IAC Catuaí 44 & 3 & 19,2 \\
IAC Catuaí 44 & 4 & 15,3 \\
\hline Rubi & 1 & 26,8 \\
Rubi & 2 & 22,0 \\
Rubi & 3 & 15,5 \\
Rubi & 4 & 14,0 \\
\hline
\end{tabular}

Teste de germinação - Foram utilizadas oito repetições de 50 sementes sem pergaminho (remoção manual), tendo como substrato rolos de papel de germinação, tipo germitest, umedecidos com água destilada na proporção de 2,5 vezes a massa do papel seco. Os rolos foram levados para germinador à temperatura de $30^{\circ} \mathrm{C}$, onde permaneceram durante período de 30 dias. Transcorrido esse período, foi realizada a avaliação de plântulas e sementes, conforme as Regras para Análise de Sementes (Brasil, 1992). Os resultados foram expressos em porcentagem de germinação, ou seja, porcentagem de plântulas normais obtidas no teste.

Após a realização de alguns ensaios preliminares para aperfeiçoamento da metodologia, onde foram testadas diferentes concentrações, tempos e forma de exposição ao hipoclorito de sódio, com a finalidade de verificar a eficiência do emprego desta substância na avaliação rápida de sementes de cafeeiro, desenvolveu-se o teste com hipoclorito de sódio, que recebeu o nome de LERCAFÉ, realizado conforme dois métodos, como se segue.
LERCAFÉ - Método 1 - Foram testados sementes com quatro períodos de armazenamento do cultivar IAC Catuaí 44 e quatro do cultivar Rubi. Para testar cada lote foram utilizadas oito repetições de 50 sementes, cujo pergaminho foi removido manualmente. Utilizando-se caixas plásticas de germinação $(11 \times 11 \times 3,5 \mathrm{~cm})$, com telado plástico, para melhor envolvimento das sementes pela solução, as sementes foram imersas em $100 \mathrm{ml}$ de hipoclorito de sódio em concentração de $2,5 \%$. As caixas contendo as sementes foram levadas para câmara de germinação, regulada à temperatura de $25^{\circ} \mathrm{C}$, onde permaneceram por três horas. Transcorrido esse período, as sementes foram lavadas e depois avaliadas.

LERCAFÉ - Método 2 - Utilizando-se oito repetições de 50 sementes com pergaminho, foram testados quatro períodos de armazenamento do cultivar IAC Catuaí 44 e quatro lotes do Cultivar Rubi. As sementes foram imersas em $100 \mathrm{ml}$ de solução de hipoclorito de sódio a $5 \%$. Para a imersão das sementes foram utilizadas caixas plásticas de germinação (11x11x3,5 cm), com telado plástico, para contato total das sementes com a solução. As sementes imersas em hipoclorito de sódio permaneceram em câmara de germinação, regulada à temperatura de $25^{\circ} \mathrm{C}$, por período de seis horas. Passado o tempo de imersão, as sementes submetidas a este método foram lavadas e imersas em água destilada por 40 minutos e, posteriormente, avaliadas.

Após o procedimento do teste LERCAFÉ, em ambas as metodologias, as sementes foram dispostas sobre bancada para avaliação visual das sementes. Foram classificadas como não germináveis as sementes que apresentavam coloração esverdeada na área ao redor e, ou sobre o embrião e as sementes que não apresentavam embrião visível, conforme critério descrito na Figura 1. A estimativa da germinação das sementes foi expressa em porcentagem, onde foi considerado o número de sementes classificadas como germináveis.

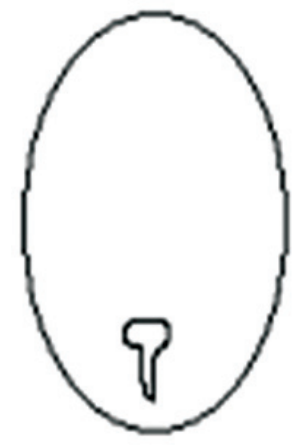

A

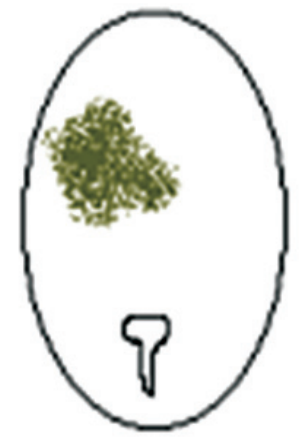

B

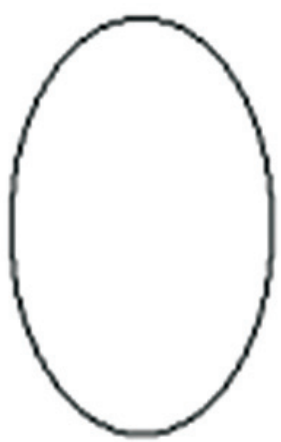

C

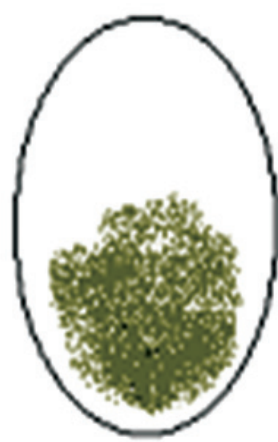

D

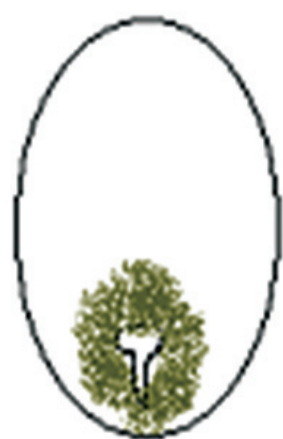

$\mathbf{E}$

FIGURA 1. Critério adotado para avaliação das sementes (A e B - sementes germináveis; C, D e E - sementes não germináveis). 
Ao término da avaliação visual, as mesmas sementes testadas, tanto pelo método 1, quanto pelo método 2, foram submetidas ao teste de germinação, com o objetivo de fazer a confirmação dos resultados encontrados no teste desenvolvido.

$\mathrm{O}$ experimento foi conduzido segundo o delineamento inteiramente casualizado, utilizando-se oito repetições de 50 sementes. Os dados foram submetidos à análise de variância e as médias comparadas pelo teste de Tukey a $5 \%$ de probabilidade. Foram calculados os coeficientes de correlação de Pearson (r) entre os métodos de estimativa da germinação (LERCAFÉ) e o teste de germinação; a significância dos valores de $\mathrm{r}$ foi determinada pelo teste $\mathrm{t}$, a 1 e 5\% de probabilidade (Gomes, 2000).

\section{RESULTADOS E DISCUSSÃO}

$\mathrm{Na}$ Tabela 2, podem ser observados os resultados de germinação encontrados nas sementes de cafeeiro. Observase que o teste de germinação agrupou os lotes em categorias de qualidade diferentes, onde se verifica que, para a cultivar IAC Catuaí 44, o teste classificou os lotes 1 e 2 como lotes superiores e o lote 4 como inferior. Já para a cultivar Rubi, os lotes 1, 2 e 3 destacaram-se como lotes de melhor qualidade e apenas o lote 4 apresentou menor qualidade em comparação aos demais, pelo teste de germinação.

TABELA 2. Germinação de quatro lotes de sementes de cafeeiro Coffea arabica L., cultivares IAC Catuaí 44 e Rubi.

\begin{tabular}{ccc}
\hline Cultivar & Lote & Germinação $(\%)$ \\
\hline IAC Catuaí 44 & 1 & $89,75 \mathrm{a}$ \\
IAC Catuaí 44 & 2 & $88,00 \mathrm{ab}$ \\
IAC Catuaí 44 & 3 & $82,75 \mathrm{bc}$ \\
IAC Catuaí 44 & 4 & $78,00 \mathrm{c}$ \\
\hline Rubi & 1 & $92,00 \mathrm{a}$ \\
Rubi & 2 & $89,00 \mathrm{a}$ \\
Rubi & 3 & $88,00 \mathrm{a}$ \\
Rubi & 4 & $80,00 \mathrm{~b}$
\end{tabular}

Médias seguidas pela mesma letra não diferem entre si, pelo teste de Tukey a $5 \%$ de probabilidade.

A avaliação visual das sementes pelo teste LERCAFÉ, de acordo com a localização da coloração esverdeada no endosperma e a visualização do embrião, permitiu o estabelecimento das estimativas de germinação dos lotes, onde se considerou viável a semente que apresentava embrião visível e nenhuma mancha esverdeada sobre ou ao redor deste. Deste modo, sementes que apresentavam coloração esverdeada em outras regiões do endosperma foram classificadas como viáveis e sementes com lesões sobre o embrião ou comprometendo regiões próximas foram classificadas como não gemináveis.

$\mathrm{Na}$ Figura 2 estão ilustradas sementes classificadas como germináveis, não apresentando nenhuma alteração de coloração em toda extensão do endosperma, após a aplicação do teste LERCAFÉ - Método 1. Exemplos de sementes que após a aplicação do teste apresentaram formação de manchas esverdeadas em regiões que provavelmente não afetam o bom desenvolvimento do embrião estão representados na Figura 3, onde é possível observar que as regiões inviáveis ou lesionadas encontramse distantes da região embrionária. Na Figura 4 são observadas sementes nas quais foram formadas manchas esverdeadas sobre a região embrionária. Sementes com essas formações foram consideradas inviáveis pelo fato de não originarem plântulas normais quando submetidas ao teste de germinação.

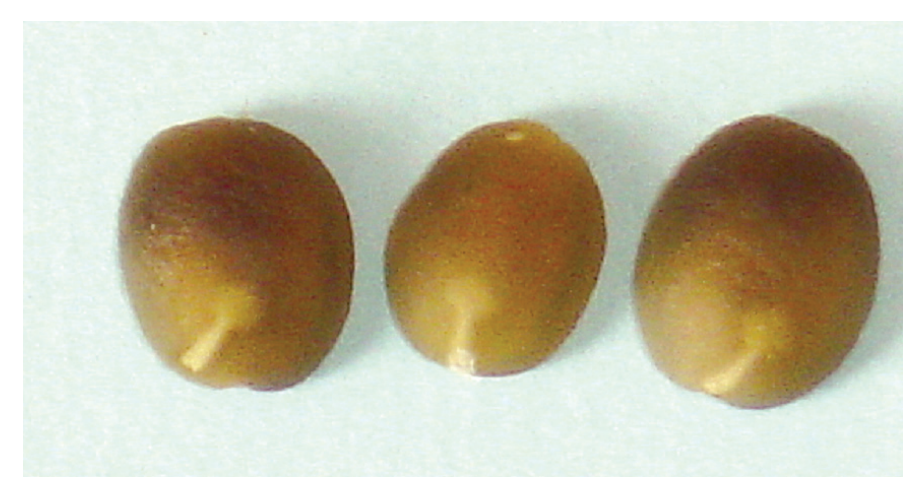

FIGURA 2. Sementes de cafeeiro após aplicação do teste LERCAFÉ - Método 1, classificadas como germináveis, apresentando embriões visíveis e nenhuma formação de coloração no endosperma.

Quando testadas pelo teste LERCAFÉ - Método 2, as sementes apresentaram as mesmas características de coloração para a estimativa da germinação. Contudo, neste método o endosperma das sementes apresentou coloração mais clara, provavelmente pelo fato das sementes terem 
sido expostas à solução por período prolongado e também terem sido imersas em água após o tratamento com hipoclorito de sódio.

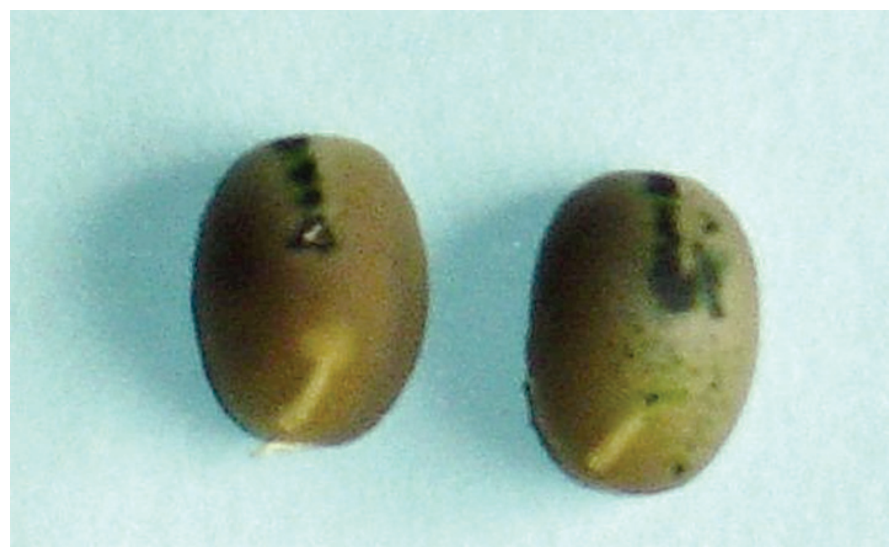

FIGURA 3. Sementes de cafeeiro após aplicação do teste LERCAFÉ - Método 1, classificadas como germináveis, apresentando formação de coloração esverdeada sobre o endosperma em regiões distantes do embrião.

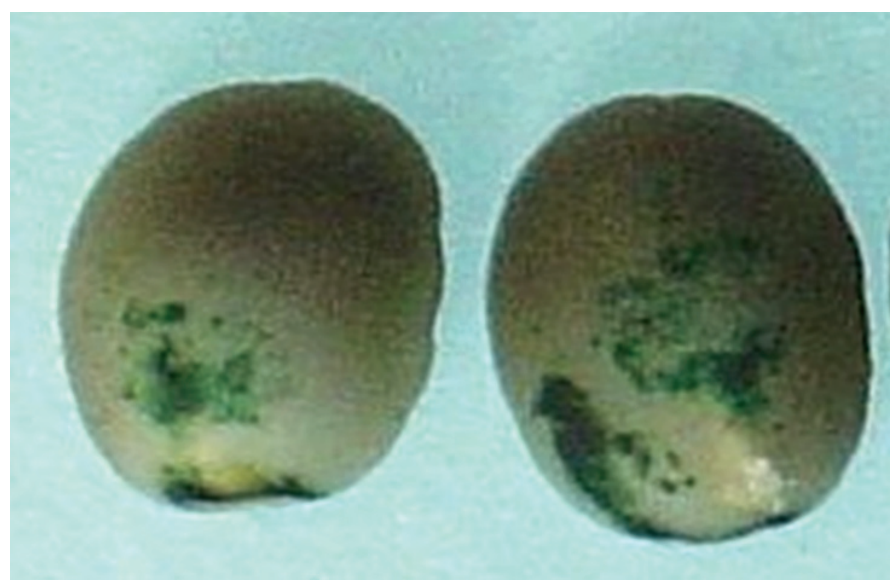

FIGURA 4. Sementes de cafeeiro após aplicação do teste LERCAFÉ - Método 1, classificadas como não germináveis, apresentando formação de coloração esverdeada sobre o endosperma, na região do embrião.

Na Figura 5 estão apresentadas sementes lesionadas (germináveis e não germináveis), caracterizadas pelo teste LERCAFÉ - Método 2. É possível observar que as sementes avaliadas por este método, apresentam maior contraste entre as manchas esverdeadas e o endosperma, além do método propiciar resultados semelhantes ao teste LERCAFÉ - Método 1.

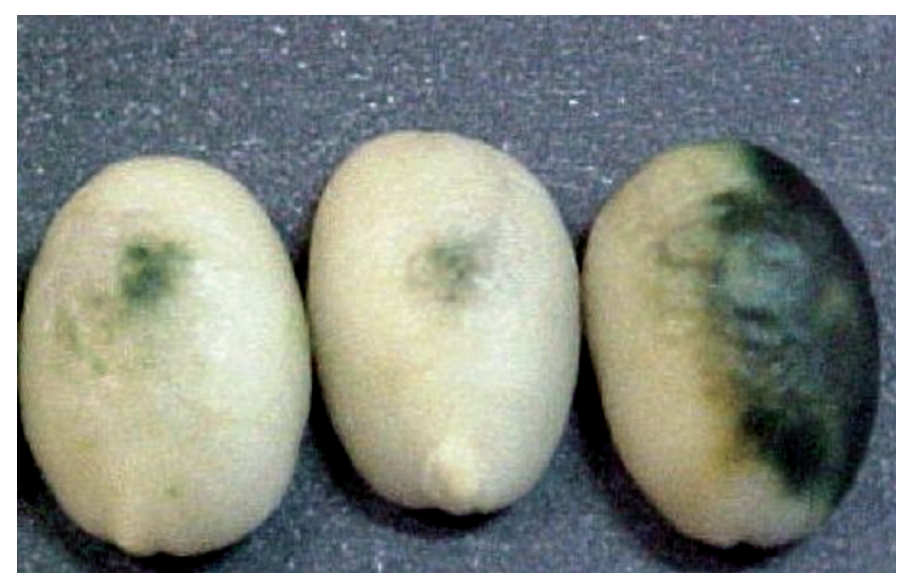

FIGURA 5. Sementes de cafeeiro após aplicação do teste LERCAFÉ - Método 2 do teste com hipoclorito de sódio. A e B: sementes germináveis (formação de coloração distante do embrião); C: semente não germinável (formação de coloração sobre o embrião).

Na Tabela 3, encontram-se as estimativas de germinação obtidas com o teste LERCAFÉ - Método 1. Verifica-se que, a exemplo do teste de germinação, este método também foi capaz de separar os lotes em diferentes categorias de viabilidade, distinguindo os melhores lotes daqueles de qualidade mais baixa.

Observa-se, para as sementes do cultivar IAC Catuaí 44, que o lote 1 apresentou maior número de sementes viáveis, sendo sua germinação estimada em 90\%, distinguindo-se do lote 4 que apresentou $78 \%$ de germinação estimada. As sementes do cultivar Rubi, quando analisadas por este método, também tiveram seus lotes diferenciados em níveis de qualidade, onde o lote 1 , com estimativa de germinação de $92 \%$, destacou-se como de qualidade superior e o lote 4 , com germinação estimada de $81,5 \%$, apresentou qualidade mais baixa. Esse comportamento também foi observado quando os lotes foram analisados pelo teste de germinação, que distinguiu o lote de melhor qualidade em relação ao lote inferior.

O método 2 do teste LERCAFÉ, como pode ser visto na Tabela 4, também estimou a germinação das sementes de cafeeiro, agrupando os lotes em diferentes níveis de viabilidade. Neste método, o lote que apresentou melhores resultados de viabilidade para a cultivar IAC Catuaí 44, foi o lote 1 , distinguindo-se do lote 4 , que obteve resultados inferiores, conforme ocorrido no método 1 e no teste de germinação. Esta tendência também foi confirmada pelos resultados apresentados com o cultivar Rubi. 
TABELA 3. Germinação estimada pelo teste LERCAFÉ - Método 1, de quatro lotes de sementes de Coffea arabica L., cultivares IAC Catuaí 44 e Rubi.

\begin{tabular}{ccc}
\hline Cultivar & Lote & $\begin{array}{c}\text { Germinação estimada (\%) } \\
\text { método 1 }\end{array}$ \\
\hline IAC Catuaí 44 & 1 & $90,00 \mathrm{a}$ \\
IAC Catuaí 44 & 2 & $89,00 \mathrm{ab}$ \\
IAC Catuaí 44 & 3 & $84,00 \mathrm{bc}$ \\
IAC Catuaí 44 & 4 & $78,00 \quad \mathrm{c}$ \\
\hline Rubi & 1 & $92,00 \mathrm{a}$ \\
Rubi & 2 & $88,50 \mathrm{ab}$ \\
Rubi & 3 & $88,00 \mathrm{ab}$ \\
Rubi & 4 & $81,50 \mathrm{~b}$ \\
\hline
\end{tabular}

Médias seguidas pela mesma letra, não diferem entre si, pelo teste de Tukey a $5 \%$ de probabilidade.

TABELA 4. Germinação estimada pelo teste LERCAFÉ - Método 2, de quatro lotes de sementes de Coffea arabica L., cultivares IAC Catuaí 44 e Rubi.

\begin{tabular}{ccc}
\hline Cultivar & Lote & $\begin{array}{c}\text { Germinação estimada }(\%) \\
\text { método } 2\end{array}$ \\
\hline IAC Catuaí 44 & 1 & $88,5 \mathrm{a}$ \\
IAC Catuaí 44 & 2 & $87,0 \mathrm{a}$ \\
IAC Catuaí 44 & 3 & $84,2 \mathrm{a}$ \\
IAC Catuaí 44 & 4 & $77,7 \mathrm{~b}$ \\
\hline Rubi & 1 & $92,0 \mathrm{a}$ \\
Rubi & 2 & $89,7 \mathrm{a}$ \\
Rubi & 3 & $88,5 \mathrm{a}$ \\
Rubi & 4 & $79,0 \mathrm{~b}$ \\
\hline
\end{tabular}

Médias seguidas pela mesma letra, não diferem entre si, pelo teste de Tukey a $5 \%$ de probabilidade.

Ao se comparar a germinação (Tabela 2), obtida com o teste de germinação e o teste LERCAFÉ nos métodos 1 e 2 (Tabelas 3 e 4) torna-se possível a verificação da semelhança entre os resultados apresentados pelas diferentes formas de avaliação das sementes, indicando, deste modo, a viabilidade da utilização do teste desenvolvido na avaliação da qualidade e estimativa da germinação das sementes de cafeeiro.

Além disso, a aplicação do hipoclorito de sódio, por meio do teste LERCAFÉ, em ambos os métodos utilizados, tornou o endosperma das sementes translúcido, possibilitando a visualização das estruturas internas e, consequentemente, a verificação e a quantificação do número de sementes dotadas de embrião. Deste modo, o teste desenvolvido, além de estimar a germinação das sementes, pode auxiliar na determinação do potencial máximo de germinação que os lotes podem alcançar em função da quantidade de sementes sem embrião encontradas nos mesmos.

Os coeficientes de correlação entre os resultados do teste de germinação e do teste LERCAFÉ (métodos 1 e 2), para o cultivar IAC Catuaí 44 encontram-se na Tabela 5. Pelos resultados obtidos para a avaliação da viabilidade verifica-se que houve correlação positiva altamente significativa $(r=0,99)$ entre os resultados de germinação (TG) e o método 1 de estimativa da germinação. A comparação entre o método 2 e o teste de germinação (TG) também gerou coeficiente de correlação bastante elevado $(r=0,97)$, para o mesmo cultivar. Do mesmo modo, porém para a cultivar Rubi (Tabela 6), a análise de correlação indicou grande correspondência entre o teste de germinação (TG) e o teste LERCAFÉ, com correlação positiva significativa $(\mathrm{r}=0,99)$, tanto para o método 1 , quanto para o método 2.

TABELA 5. Coeficientes de correlação de Pearson entre os resultados dos testes de germinação (TG) e o teste LERCAFÉ (métodos 1 e 2), realizados em quatro lotes de sementes de Coffea arabica L., cultivar IAC Catuaí 44.

\begin{tabular}{cccc}
\hline & TG & MÉTODO 1 & MÉTODO 2 \\
\hline TG & 1 & $0,994^{* *}$ & $0,975^{* *}$ \\
MÉTODO 1 & & 1 & $0,989^{* *}$ \\
MÉTODO 2 & & & 1 \\
\hline
\end{tabular}

** Significativo a $1 \%$ de probabilidade pelo teste $\mathrm{t}$.

As elevadas correlações encontradas entre as duas metodologias do novo teste proposto e o teste de germinação também indicam o grande potencial do método quanto à avaliação rápida da qualidade das sementes de cafeeiro, podendo trazer muitos benefícios para os setores envolvidos com a cultura como a comercialização antecipada dos lotes de sementes, uma vez que o teste de germinação demora 30 dias para fornecer os resultados. 
TABELA 6. Coeficientes de correlação de Pearson entre os resultados dos testes de germinação (TG) e o teste LERCAFÉ (métodos 1 e 2), realizados em quatro lotes de sementes de Coffea arabica L., cultivar Rubi.

\begin{tabular}{cccc}
\hline & TG & MÉTODO 1 & MÉTODO 2 \\
\hline TG & 1 & $0,995^{* *}$ & $0,996^{* *}$ \\
MÉTODO 1 & & 1 & $0,983^{* *}$ \\
MÉTODO 2 & & & 1 \\
\hline
\end{tabular}

** Significativo a $1 \%$ de probabilidade pelo teste $\mathrm{t}$.

A avaliação rápida também favorece a produção de mudas de qualidade em menor tempo e, consequente instalação da lavoura em épocas adequadas. A obtenção de dados referentes à germinação das sementes pode agilizar e facilitar a obtenção de resultados, em trabalhos de pesquisa, com disponibilidade mais rápida dos novos conhecimentos. Além disso, os testes rápidos conhecidos, como o de tetrazólio, são de difícil execução, trabalhosos, exigem mãode-obra especializada e ainda não apresentam metodologias bem definidas para as sementes de cafeeiro.

Carbonell et al. (1993), embora estudando danos mecânicos em sementes de soja, concluíram que o uso do hipoclorito de sódio para quantificação de danos mecânicos nas sementes é pouco oneroso e requer período curto para a avaliação em comparação ao teste de tetrazólio, destacando que o teste do hipoclorito de sódio não requer grande emprego de mão-de-obra.

Comparando-se os dois métodos do teste com hipoclorito de sódio LERCAFÉ, observa-se que ambos apresentaram altas correlações com o teste de germinação, para os dois cultivares estudados. Contudo, cada metodologia apresenta particularidades em sua aplicação, definindo, portanto, sua empregabilidade de acordo com a disponibilidade de tempo e mão-de-obra do laboratório de análise. O uso do método 1, onde é utilizado o hipoclorito de sódio em concentração de $2,5 \%$, em sementes sem o pergaminho, fornece resultados precisos rapidamente. Em contrapartida, a utilização da segunda metodologia, onde é usada concentração superior do produto (5\%), não é necessário que o pergaminho seja retirado manualmente, uma vez que o hipoclorito de sódio, neste caso, promove a degradação desta estrutura. Tal observação também foi feita por Meireles et al (2007) que verificaram que a imersão das sementes de cafeeiro em solução de hipoclorito de sódio na concentração de
$5 \%$ por seis horas promoveu a degradação do pergaminho de modo a não causar danos ao processo germinativo das sementes.

O emprego do teste LERCAFÉ pode contribuir de maneira significativa para o setor de tecnologia de sementes de cafeeiro, auxiliando na tomada de decisões no que diz respeito ao diagnóstico sobre a qualidade do lote, já que esse produto possibilita a visualização das estruturas essenciais para a germinação e ainda torna possível a identificação das partes da semente que se encontram danificadas mecânica ou fisiologicamente, o que pode impedir o perfeito desenvolvimento das plântulas.

Logo após a avaliação das sementes pelos dois métodos do teste desenvolvido, as mesmas foram submetidas ao teste de germinação, onde as plântulas obtidas permitiram a confirmação dos resultados encontrados na avaliação visual das sementes (Tabela 7).

TABELA 7. Germinação de sementes de cafeeiro (Coffea arabicaL.), cultivares IAC Catuaí 44 e Rubi, após serem submetidas à exposição em soluções de hipoclorito de sódio pelo teste LECAFÉ.

\begin{tabular}{cccc}
\hline \multirow{2}{*}{ Cultivar } & \multirow{2}{*}{ Lote } & \multicolumn{2}{c}{ Germinação (\%) } \\
\cline { 3 - 4 } & & MÉTODO 1 & MÉTODO 2 \\
\hline IAC Catuaí 44 & 1 & 90,00 & 88,00 \\
IAC Catuaí 44 & 2 & 87,75 & 87,00 \\
IAC Catuaí 44 & 3 & 83,90 & 83,20 \\
IAC Catuaí 44 & 4 & 77,00 & 77,00 \\
\hline Rubi & 1 & 92,20 & 92,00 \\
Rubi & 2 & 88,00 & 89,00 \\
Rubi & 3 & 87,00 & 87,20 \\
Rubi & 4 & 81,00 & 79,00 \\
\hline
\end{tabular}

$\mathrm{Na}$ Figura 6 encontram-se ilustradas as plântulas oriundas de sementes de diferentes categorias, classificadas pelo teste LERCAFÉ, tanto no método 1, quanto no método 2. Ao se observar a figura, verifica-se que as sementes que revelaram manchas de coloração verde sobre o embrião não emitiram a raiz primária. Sementes que apresentaram formação de manchas verdes ao redor da região embrionária emitiram a raiz primária, porém não foram capazes de originar plântulas normais. Quando as manchas esverdeadas se concentraram em regiões distantes 
do eixo embrionário, as sementes germinaram, resultando em plântulas normais. Já as sementes que não apresentaram nenhuma lesão em toda a extensão do endosperma também originaram plântulas normais com desenvolvimento superior ao das demais.

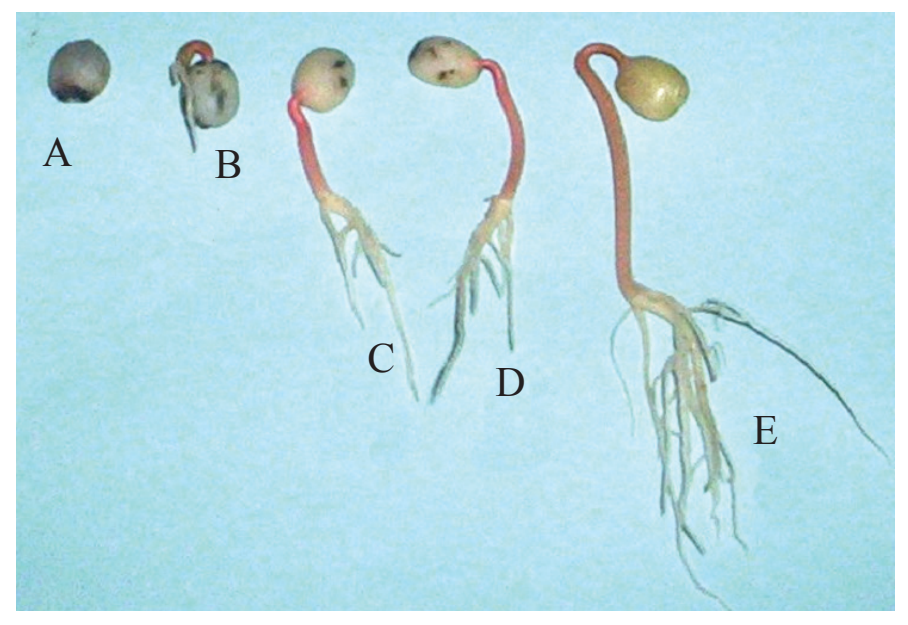

FIGURA 6. Plântulas originadas de sementes submetidas ao teste LERCAFÉ. A: semente não germinada; B: plântula anormal; C e D: plântulas normais oriundas de sementes coloridas; $E$ : plântula normal oriunda de semente sem coloração esverdeada.

Em função da metodologia utilizada com lotes de sementes com uma grande amplitude de germinação de dois cultivares e com os resultados obtidos é possível considerar o teste LERCAFÉ como um teste rápido de características não destrutivas, onde o hipoclorito de sódio é empregado com finalidade colorimétrica e não de escarificação intensa, possibilitando a avaliação das plântulas. Além disso, as duas metodologias do teste desenvolvido se mostraram simples, de fácil execução, de baixo custo e bastante eficazes quanto aos resultados.

\section{CONCLUSÕES}

O teste LERCAFÉ pode ser utilizado para avaliar o potencial germinativo de semente de café de maneira rápida e precisa.

O teste LERCAFÉ apresenta baixo custo, é de fácil execução e interpretação, podendo ser utilizado como teste rotineiro;

Por possuir características não destrutivas, o teste LERCAFÉ permite a avaliação das plântulas provenientes das sementes testadas, para confirmação dos resultados.

\section{AGRADECIMENTOS}

Ao CNPq pela concessão de bolsa.

\section{REFERÊNCIAS}

BRASIL, Ministério da Agricultura e da Reforma Agrária. Secretária Nacional de Defesa Agropecuária. Departamento Nacional de Produção Vegetal. Coordenação de Laboratório Vegetal. Regras para análise de sementes. Brasília, DF, 1992. 365p.

CARBONELL, S.A.M.; KRZYZANOWSKI, F.C.; OLIVEIRA, M.C.N.; FONSECA JÚNIOR, N.S. Teor de umidade das sementes de soja e métodos de avaliação do dano mecânico provocado no teste do pêndulo. Pesquisa Agropecuária Brasileira, v.28, n.11, p.1277-1285, 1993.

DIAS, M.C.L.L.; SILVA, W.R. Determinação da viabilidade de sementes de café através do teste de tetrazólio. Pesquisa Agropecuária Brasileira, v.21, n.11, p.1139-1145, 1986.

FERNANDES, E.J.; SADER, R.J.; CARVALHO, N.M. Viabilidade de sementes de feijão (Phaseolus vulgares L.) estimada pelo $\mathrm{pH}$ do exsudato. Revista Brasileira de Sementes, v.9, n.3, p.69-75, 1987.

GOMES, F.P. Curso de estatística experimental. 14. ed. Piracicaba: USP/ESALQ, 2000. 477p.

KIKUTI, A.L.P. Aplicação de antioxidantes em sementes de cafeeiro (Coffea arabica $\mathrm{L}$.) visando a preservação da qualidade. Lavras: UFLA, 2000. 72f. Dissertação (Mestrado em Fitotecnia). Universidade Federal de Lavras, Lavras, 2000 .

MEIRELES, R.C.; ARAÚJO,E.F.; REIS, M.S.; SEDIYAMA, C.S.; SAKIYAMA, N.S.; REIS, L.S. SECAFÉ: Metodologia para acelerar a germinação das sementes de café. Revista Brasileira de Sementes, v.29, n.3, p.90-96, 2007. 